\title{
Helicobacter pylori infection: approach of primary care physicians in a developing country Shahid Ahmed ${ }^{* \dagger}$, Mohammad Salih ${ }^{\dagger}$, Wasim Jafri ${ }^{\dagger}$, Hasnain Ali Shah ${ }^{\dagger}$ and Saeed Hamid ${ }^{\dagger}$
}

Address: Section of Gastroenterology, Department of Medicine, Aga Khan University Hospital, Karachi, Pakistan

Email: Shahid Ahmed* - shahid.ahmed@aku.edu; Mohammad Salih - mohammad.salih@aku.edu; Wasim Jafri - wasim.jafri@aku.edu; Hasnain Ali Shah - hasnain.alishah@aku.edu; Saeed Hamid - saeed.hamid@aku.edu

* Corresponding author †Equal contributors

Published: 9 April 2009

BMC Gastroenterology 2009, 9:23 doi:I0.1 I86/147|-230X-9-23
Received: 14 October 2008

Accepted: 9 April 2009

This article is available from: http://www.biomedcentral.com/l47/-230X/9/23

(C) 2009 Ahmed et al; licensee BioMed Central Ltd.

This is an Open Access article distributed under the terms of the Creative Commons Attribution License (http://creativecommons.org/licenses/by/2.0), which permits unrestricted use, distribution, and reproduction in any medium, provided the original work is properly cited.

\section{Abstract}

Background: The aim of the study was to assess the knowledge and practices of primary care physicians in diagnosis and management of Helicobacter pylori $(H$. pylori) infection in developing country.

Methods: This convenient sample based, cross sectional study was conducted in primary care physicians of Karachi, Pakistan from March 2008 to August 2008 through a pretested self-designed questionnaire, which contained II items pertaining to $H$. pylori route of transmission, diagnosis, indication for testing, treatment options, follow up and source of information.

Results: Out of 509 primary care physicians, 45 I consented to participate with the response rate of $88.6 \%$. Responses of 426 primary care physicians were analyzed after excluding 19 physicians. $78 \%$ of the physicians thought that contaminated water was the source of spread of infection, dyspepsia was the most frequent indication for investigating $H$. pylori infection $(67 \%$ of the physicians), while $43 \%$ physicians were of the view that serology was the most appropriate test to diagnose active $H$. pylori infection. $77 \%$ of physicians thought that gastric ulcer was the most compelling indication for treatment, $61 \%$ physicians preferred Clarithromycin based triple therapy for 7-I 4 days. $57 \%$ of the physicians would confirm $H$. pylori eradication after treatment in selected patients and $47 \%$ physicians preferred serological testing for follow-up. In case of treatment failure, only $36 \%$ of the physicians were in favor of gastroenterologist referral.

Conclusion: The primary care physicians in this study lacked in knowledge regarding management of $H$. pylori infection. Internationally published guidelines and World gastroenterology organization (WGO) practice guideline on $\mathrm{H}$. pylori for developing countries have little impact on current practices of primary care physicians. We recommend more teaching programs, continuous medical education activities regarding $H$. pylori infection. 


\section{Background}

The world wide prevalence of $H$. pylori is more than 50\% $[1,2]$. It is more prevalent in developing countries as compared to developed countries [3]. Its prevalence in South Asia is ranging between 55 to $90 \%$ [4].

H. pylori infection is prevalent in more than $90 \%$ of peptic ulcer disease patients and the risk of bleeding from peptic ulcer increases by 1.79 times in patients with this infection as compared to controls [5]. Its successful eradication can prevent the ulcer relapse [6-8]. Similarly, in patients with non-ulcer dyspepsia the eradication of $H$. pylori may lead to improvement of symptoms [9].

In 1983, the concepts of etiology, pathogenesis and management of upper gastrointestinal (UGI) diseases have changed altogether after the successful isolation of $H$. pylori organism [10]. This has led to a number of H. pylori related information and the development of international guidelines. Majority of patients with dyspepsia are managed by primary care physicians and several educational initiatives have been undertaken to educate them regarding the appropriate diagnosis and management of this infection $[11,12]$. However, the results from several internationally published surveys from different developed countries have revealed that significant confusion still exists and discrepancies are present in the understanding of $H$. pylori among primary care physicians with respect to the pathogenesis, diagnosis and treatment [10]. The major uncertainties are in the management of patients with dyspepsia where the primary care physicians need to make a decision whether to test for $H$. pylori infection and treat if positive, or refer patients to a specialist $[13,14]$.

There is scarce data from South Asia regarding the knowledge and practices of primary health care providers about $H$. pylori infection. The aim of this study was to assess the knowledge and practices of primary care physicians in the diagnosis and management of $H$. pylori infection in our country and to highlight the gaps in knowledge and management so that these areas can be focused in future continuous medical educational activities for primary care physicians.

\section{Methods \\ Study design}

This was cross sectional study in primary care physicians of Karachi, Pakistan. In this survey non probability convenient sampling technique was used.

\section{Sample size}

We calculated sample size based two facts; the number of primary care physician in the city (4025, physicians) http://www.paksehat.com/[15] and the assumption that
$50 \%$ of the practicing physicians lack in proper knowledge regarding management of $H$. pylori infection. With $95 \%$ confidence level, bound on error of $5 \%$ a sample size of 352 was calculated. The sample size was further inflated by $20 \%$ to adjust for non-responders, so the final sample size of 422 participants was calculated.

\section{Sample selection}

Inclusion criteria

- Practicing primary care physicians seeing more than 20 patients per day in clinic and in practice for more than 2 years.

\section{Exclusion Criteria}

Primary care physicians were excluded if they fulfilled any of the following criteria;

- Non practicing primary care physicians,

- Physicians who have postgraduate diploma in medicine,

- Physicians who have attended national or international conferences on $H$. pylori/peptic ulcer disease management or related seminar/work shop in past 2 years.

\section{Data collection procedure}

This cross sectional study was conducted from March 2008 to August 2008. A self administered pretested proforma with closed ended questions was used (see Additional file 1). The questionnaire contained 11 items pertaining to $H$. pylori infections; the route of transmission, knowledge of diagnosis, indication for testing, treatment options, duration of treatment, treatment regimens, follow up testing, referral to specialist and source of information of the primary care physicians. After written informed consent, the responses of primary care physicians were recorded on questionnaire during various nonrelated CME activities organized by the Aga Khan University Hospital and also the physicians were approached in their respective clinics on convenient basis. A total of 509 primary care physicians were approached with the response rate of $88.6 \%$. Proforma was filled individually by each primary care physician without the help of any other person.

This study was also approved by Ethical review committee of The Aga Khan University Hospital, Karachi, Pakistan.

\section{Data analysis procedure}

Statistical Packages for Social Sciences (S.P.S.S.) version 16 (Chicago Inc.) was used for entering and analysis of 
data. Charts and graphs were plotted using computerized program Microsoft Office (XP Professional) 2003.

The results were expressed as mean \pm standard deviation or median with ranges for all continuous variables (e.g., age, years of practice, antibiotic use in days, PPI use in days) and numbers (percentage) for categorical data (e.g., gender, source of information about $H$. pylori).

\section{Results}

Out of 509 primary care physicians, 451 consented to participate with the response rate of $88.6 \%$. 19 were excluded as they had attended the workshops or seminars on $H$. pylori infection in last 2 years and proforma of 6 physicians were incomplete, so finally the responses of 426 primary care physicians were analyzed.

\section{Socio-demographic characteristics}

The mean age and working years of the primary health care physicians were $42.38 \pm 9.31$ and $13.38 \pm 7.73$ years respectively; $315(73.94 \%)$ of primary health care physicians were males.

The responses of the primary care physicians to different questions (Study questionnaire attached) related to $H$. pylori infection are as follows:

\section{I) Route of transmission for $\mathrm{H}$. pylori infection}

The knowledge about the route of transmission was checked through options like, contaminated water, contaminated endoscopes, blood products or needle injures. They could select more than one option. Out of 426 primary care physicians, 308 (72.3\%) thought that contaminated water is mainly the source of spread, (Figure 1).

\section{2) Indications for testing $H$. pylori infection}

Out of 426 primary care physicians, 287 (67\%) opted for dyspepsia as the number one indication for investigating H. pylori, followed by gastroesophageal reflux diseases (GERD), gastritis, gastric and duodenal ulcers, iron defi-

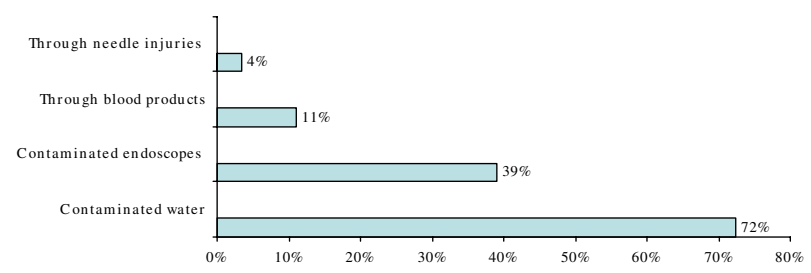

Figure I

Route of transmission for $\boldsymbol{H}$. pylori infection. ciency anemia. Details of responses are given in Figure 2. Physicians could select any number of indications.

\section{3) Appropriate test for detection of active $H$. pylori infection}

The physicians were asked which one diagnostic test they would choose for active $H$. pylori infection. As the single best test; 183 (43\%) physicians would check serology (IgG antibody) for diagnosis (Figure 3).

\section{4) Treatment indications for $\mathrm{H}$. pylori infection}

Physicians were asked when they would treat $H$. pylori. They were given with various options, shown in figure 4 and were allowed to select as many as they thought were appropriate. In reply 328 (77\%) primary care physicians thought that gastric ulcer is the most compelling indication for the H. pylori eradication (Figure 4).

\section{5) $H$. pylori eradication in non ulcer dyspepsia}

Physicians were asked whether $H$. pylori eradication in non ulcer dyspepsia (NUD) was always/sometimes/on the patient request or never required. On one best selection basis 237 (55\%) physicians would sometimes eradicate H. pylori in NUD patients (Figure 5).

\section{6) Eradication regimens as first line treatment}

The physicians were inquired of their first choice of $H$. pylori eradication regimen. For which various standard regimens were given and they had to select one best first line treatment option. Clarithromycin, amoxicillin, proton pump inhibitor based triple therapy was used as first line treatment by 261 (61\%) physicians (Figure 6).

\section{7) Appropriate duration for treating $H$. pylori infection}

Regarding the treatment duration different options were given, 396 (93\%) physicians would treat for 7-14 days. Only 30 (7\%) physicians wanted to treat for more than 2 weeks.

\section{8) Confirmation of $\mathrm{H}$. pylori eradication}

Eradication of $H$. pylori was confirmed by 247 (57\%) of physicians in selected patients only (Figure 7 ).

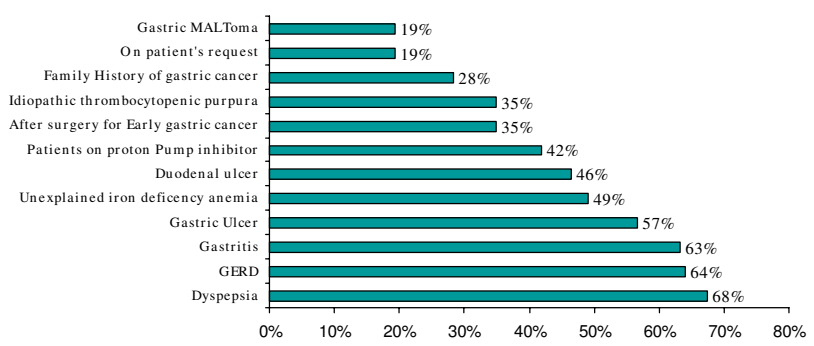

Figure 2

Indications for testing $\boldsymbol{H}$. pylori infection. 


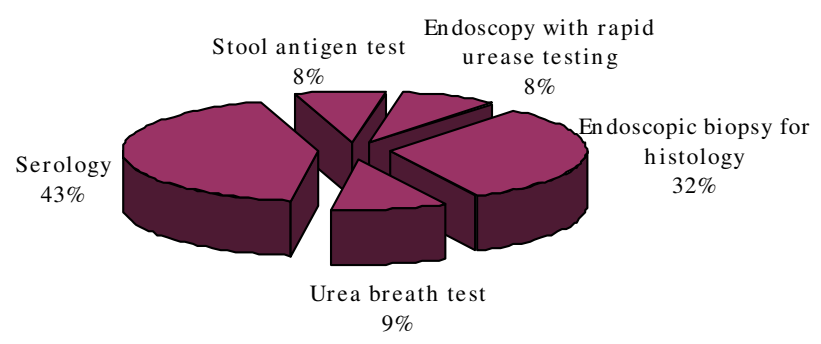

Figure 3

Appropriate test for detection of active $\boldsymbol{H}$. pylori infection.

9) Test for documenting $H$. pylori eradication

H. pylori serology was the preferred follow up test for successful eradication by 201 (47\%) physicians, followed by 149 (35\%) urea breath test. Few physicians 38 (9\%) would ask for endoscopy with rapid urease test or endoscopy with histology based testing in 17 (4\%). While 21 (5\%) physicians would use $H$. pylori stool antigen test for the confirmation of eradication.

10) Treatment plan after failure to eradicate $H$. pylori infection Only 155 (36\%) of the physicians would refer the patient to gastroenterologist in case of primary treatment failure, the responses to different options are shown in Table 1.

II) Most common source of information about $H$. pylori infection Only 135 (32\%) primary care physicians were using medical journals as a source of information on $H$. pylori infection followed by text book reading in 101 (23\%), pharmaceutical companies provided literature in 77 (18\%), respectively. Only 60 (14\%) physicians would attend workshop/conferences on any topic to update their knowledge and 53 (13\%) physicians would use internet.

\section{Discussion}

This study was aimed to gauge the current practices, understanding and approaches of primary care physicians

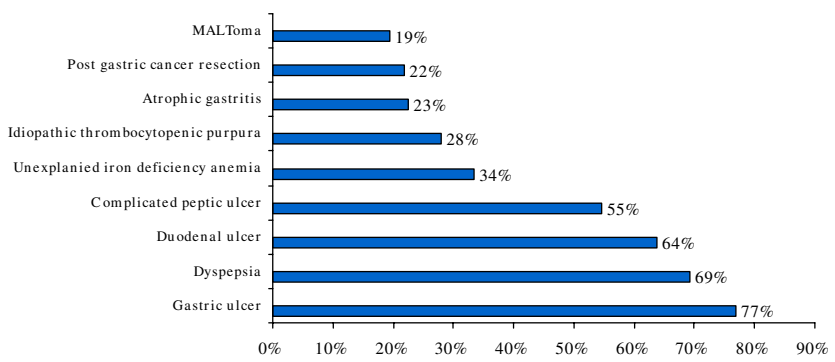

Figure 4

Treatment indications for $H$. pylori infection.

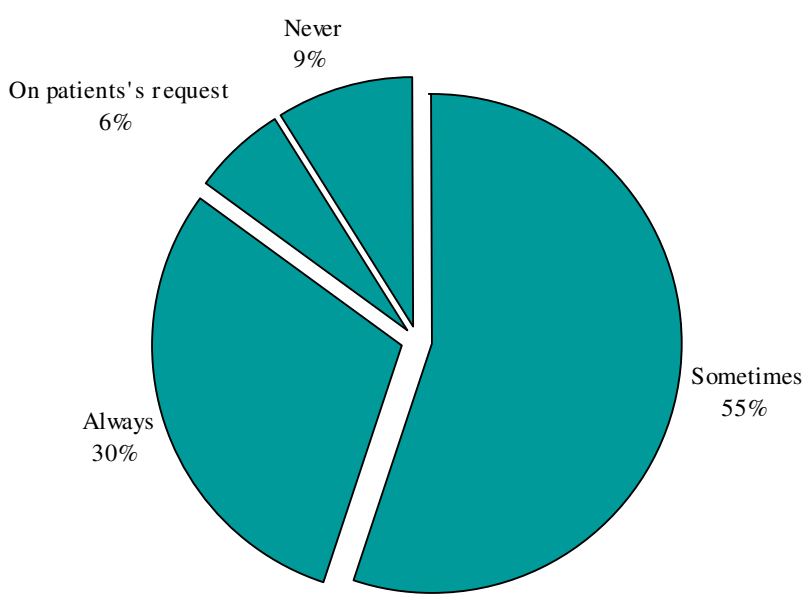

Figure 5

$H$. pylori eradication in non ulcer dyspepsia.

regarding the management of $H$. pylori infection in the largest city of Pakistan. In the current era the knowledge and evidence in the management of various diseases is expanding very fast and different national and international societies are coming up with evidence based guidelines but their impact at the primary care level is not well studied especially in developing countries. A Korean study revealed that guidelines on the management of $H$. pylori have a little impact on clinical practice in Korea [16]. Another survey from Turkey on 109 general practitioners also pointed out the gaps in practice [17]. Similarly, a study from Italy at 100 randomly selected general practitioners showed that uncertainty seems to persist regarding indications for $H$. pylori treatment, the use of diagnostic testing, and patients follow-up [18].

Our study reflected the existing knowledge of $H$. pylori infection among the primary health care physicians in Karachi, Pakistan. Majority (72\%) of physicians in this study believed that $H$. pylori infection is transmitted through contaminated water; however, 14\% physicians thought that it was transmitted either through the blood products or by needle stick injuries. Primary care physicians would usually advise $H$. pylori testing in cases of gastric ulcer, duodenal ulcer and dyspepsia in 56\%, 46\% and $67 \%$ of the times respectively. In our study only $19 \%$ physicians thought that MALToma is an indication for investigating $H$. pylori and $35 \%$ were of the opinion that it should be investigated after surgery for early gastric cancer. Almost similar inferences were concluded from Korean study; in that study $26.9 \%$ of primary care physicians would opt for testing $H$. pylori in patients after surgery for early gastric cancer and $13 \%$ of the physicians would check it in MALToma [16]. Majority of physicians in the current study preferred serological or biopsy based 


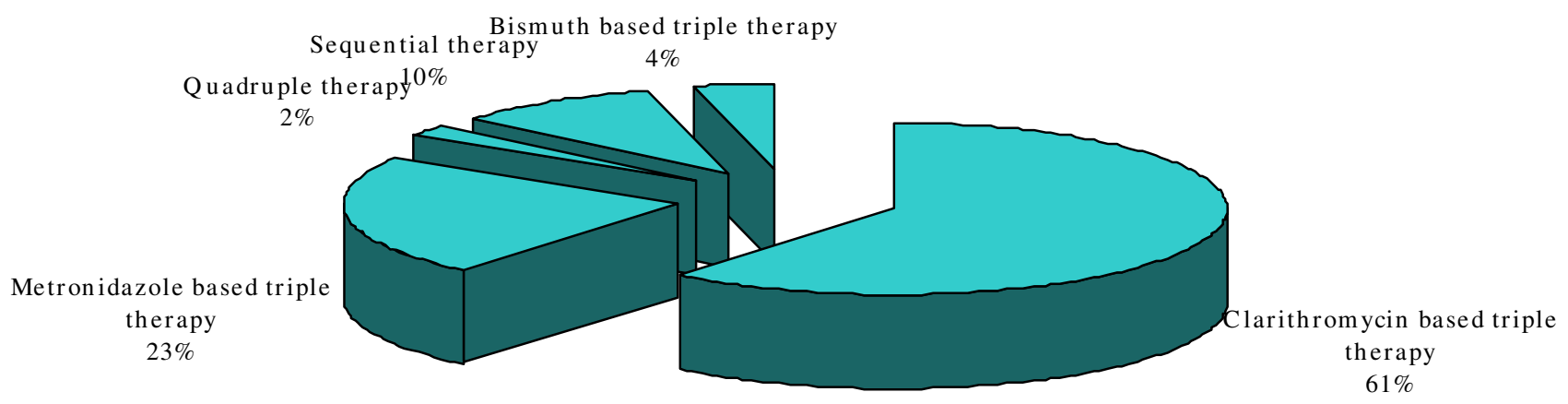

\section{Figure 6}

Eradication regimens as first line treatment.

testing of $H$. pylori in $43 \%$ and $32 \%$, respectively. While only $22 \%$ of Korean primary care physician opted for serology as a first test for detecting H. pylori while 55\% of Italian physicians preferred gastroscopy with biopsies as initial diagnostic testing $[16,18]$. About $88 \%$ primary care physicians in this study were treating $H$. pylori for 7-14 days which was similar to Korean study, 90\% of Korean physicians were in favor of 7 to 14 days treatment [16]. In this study, only $12 \%$ of primary care physicians always ordered follow-up testing after $H$. pylori treatment as compared to Korean primary care physicians who would do follow-up testing in 9.3\% cases which is in contrast to Italian physicians' practices. About $50 \%$ of Italian physicians thought it was useful to repeat endoscopy with biopsy after treatment to document eradication while $47 \%$ of our primary care physicians used serology as follow up test [18]. In contrast the only $6.5 \%$ Korean physicians used serology as a follow up test [16]. Only $4.5 \%$ physicians in our study prescribed the same regimen after first line treatment failure to eradicate $H$. pylori as compared to $40.7 \%$

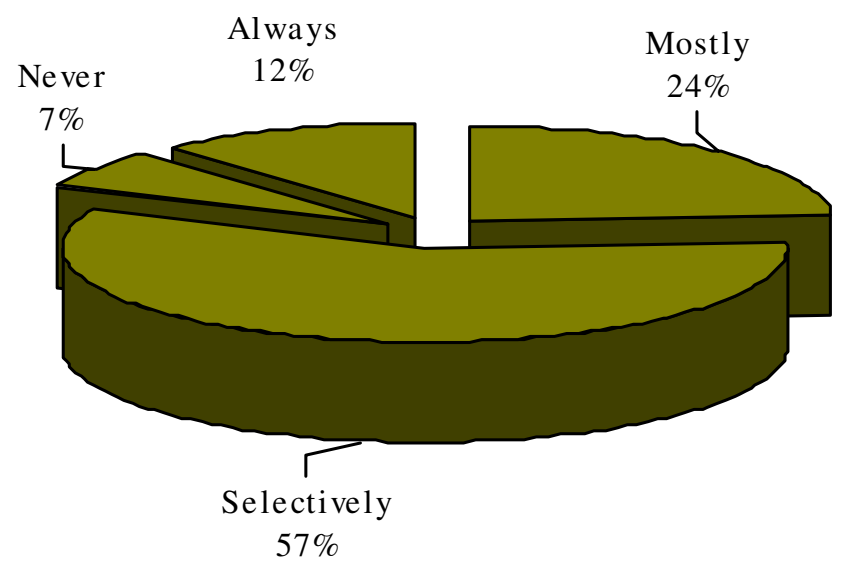

Figure 7

Confirmation of $H$. pylori eradication.
Korean Physicians who wanted to retreat with same regimen. However, $36 \%$ physicians in the current study would refer the patients to gastroenterologist after first treatment failure while only $5.6 \%$ of Korean Physicians would do the same. Similarly $25 \%$ of Italian physicians were referring to specialist [18]. More than half (55\%) of physicians in this study opted to treat $H$. pylori in non ulcer dyspepsia patients as compared to $58.3 \%$ of Korean physicians [16]. Medical journals were the source of information/knowledge for $32 \%$ of our primary care physicians, while in Turkey the main source of information to primary care physicians was pharmaceutical company sponsored symposia [17].

One of the limitations to this study is that it only reflects the approach of the primary care physicians living in Karachi, Pakistan, which may not be the true reflection of the whole county and also of other parts of the world. However, this is a first study of 426 primary care physicians from South Asia which reflects the existing knowledge, attitude and practices on the management of $H$. pylori in this endemic area. So the findings in our study endorse and highlight the gaps in practices of primary care physicians and the recommended practice guidelines for the management of $H$. pylori infection. The results of this study are pretty much similar to published data from other parts of the world.

\section{Conclusion}

The primary care physicians in this part of the world lack in knowledge regarding management of $H$. pylori infection. Internationally published guidelines and World gastroenterology organization (WGO) practice guideline on $H$. pylori infection for developing countries have little impact on current practices of primary care physicians. We recommend more teaching programs and continuous medical education activities for primary care physicians 
Table I: Treatment plan after failure to eradicate $H$. pylori

\begin{tabular}{lcc}
\hline Options & Number of doctors & Percentage(\%) \\
\hline Repeat triple therapy & 66 & $15 \%$ \\
Triple therapy with change of antibiotics & 86 & $21 \%$ \\
Quadruple therapy & 85 & $20 \%$ \\
Observation without treatment & 34 & $8 \%$ \\
Refer to gastroenterologist & 155 & $36 \%$ \\
\hline
\end{tabular}

by government, public and private sector academic institutions.

\section{Competing interests}

The authors declare that they have no competing interests.

\section{Authors' contributions}

SA and MS conceived, designed and coordinated the study. WJ, HAS, SH participated in its design, coordination and manuscript. All authors have read and approved the final manuscript.

\section{Additional material}

\section{Additional file 1}

Helicobacter pylori infection: Approach of primary care physicians in a developing country. Performa used in the study.

Click here for file

[http://www.biomedcentral.com/content/supplementary/1471230X-9-23-S1.doc]

\section{Acknowledgements}

Mr. Muhammad Islam for data analysis. Dr. Sajjad Jamil and Mr. Shuaib Ahmed for their help in data collection.

\section{References}

I. Taylor DN, Blaser MJ: The epidemiology of Helicobacter pylori infection. Epidemiol Rev 1991, 13:42-59.

2. Parsonnet J: Helicobacter pylori. Infect Dis Clin North Am 1998, I 2(I): 185-197.

3. Frenck RW Jr, Clemens J: Helicobacter in developing world. Microbes Infect 2003, 5:705-713.

4. Hunt RH, Xiao SD, Megraud F, Bazzoli F, Hamid S, Vakil N, Malfertheiner P, Leon-Barua R, Merwe SV, Wong BCY, Goh KL, Cohen H, Coeecho LG, Fock KM, Fefail S, Krahshuis JH: Helicobacter pylori in developing countries. WGO Practice Guideline 2006 [http:// www.omge.org/assets/downloads/en/pdf/guidelines/ II helicobacter pylori developing countries en.pdf].

5. Huang JQ, Sridhar S, Hunt RH: Role of Helicobacter pylori infection and non-steroidal anti-inflammatory drugs in pepticulcer disease: a meta-analysis. Lancet 2002, 359:14-22.

6. Marshall B]: Helicobacter pylori. Am J Gastroenterol 1994, 89:SII6-128.

7. Rauws EA, Tytgat GN: Cure of duodenal ulcer associated with eradication of Helicobacter pylori. Lancet 1990, 335:233-235.

8. Graham DY, Lew GM, Klein PD, Evans DG, Evans DJ, Saeed ZA, Malaty HM: Effect of treatment of Helicobacter pylori infection on the long-term recurrence of gastric or duodenal ulcer. A randomized, controlled study. Ann Intern Med 1992, I 16:705-708.
9. Moayyedi P, Deeks J, Talley NJ: An update of the Cochrane systemic review of Helicobacter pylori eradication therapy in nonulcer dyspepsia: resolving the discrepancy between systemic reviews. Am / Gastroentrol 2003, 98:2621-2626.

10. Huang J, Lam SK, Malfertheiner P, Hunt RH: Has education about Helicobacter pylori infection been effective? Worldwide survey of primary care physicians. J Gastroenterol Hepatol 2003, 18:512-520.

II. NIH Consensus Conference. Helicobacter pylori in peptic ulcer disease. NIH Consensus Development Panel on Helicobacter pylori in Peptic Ulcer Disease. JAMA 1994, 272:65-69.

12. Weijnen CF, Numans ME, de Wit NJ, Smout AJ, Moons KG, Verheij T], Hoes AW: Testing for Helicobacter pylori in dyspeptic patients suspected of peptic ulcer disease in primary care: cross sectional study. BM] 200I, 323:7I-75.

13. Howden $\mathrm{CW}$, Hunt RH: Guidelines for the management of Helicobacter pylori infection. Ad Hoc Committee on Practice Parameters of the American College of Gastroenterology. Am J Gastroenterol 93:2330-2338.

14. Howden CW: For what conditions is there evidence-based justification for treatment of Helicobacter pylori infection? Gastroenterology 1997, I I 3:S I07-I I 2

15. Media Publications: The Karachi City: Physicians directory. [On line]. 2005 [http://www.paksehat.com]. [cited June 25, 2008]

16. Kim BG, Kim JM, Jeong JB, Jung YJ, Lee KL: Discrepancies between primary physician practice and treatment guidelines for Helicobacter pylori infection in Korea. World J Gastroenterol 2006, I 2(I):66-69.

17. Canbaz S, Sunter AT, Peksen Y, Leblebicioglu H: Survey of general practitioners' knowledge about Helicobacter pylori infection. BMC Gastroenterol 2005, 5:4

18. Maconi G, Tosetti C, Miroglio G, Parente F, Colombo E, Sainaghi M, Bianchi Porro G: Management of Helicobacter Pylori-related gastrointestinal diseases by general practitioners in Italy. Aliment Pharmacol Ther 1999, I3(I I):1499-1504.

\section{Pre-publication history}

The pre-publication history for this paper can be accessed here:

http://www.biomedcentral.com/1471-230X/9/23/pre pub

Publish with Bio Med Central and every scientist can read your work free of charge

"BioMed Central will be the most significant development for disseminating the results of biomedical research in our lifetime. "

Sir Paul Nurse, Cancer Research UK

Your research papers will be:

- available free of charge to the entire biomedical community

- peer reviewed and published immediately upon acceptance

- cited in PubMed and archived on PubMed Central

- yours - you keep the copyright 